\title{
Community interpreters versus intercultural mediators
}

\author{
Is it really all about ethics?
}

\author{
Nike K. Pokorn and Tamara Mikolič Južnič \\ University of Ljubljana
}

This article compares the professional profile of community interpreters to that of a particular group of intercultural mediators who work as nonprofessional, untrained interpreters, mainly in healthcare settings. Through a textual comparison of 13 deontological documents for community interpreters and intercultural mediators, this article investigates differences in the ethical positioning of these two profiles. The results show that while the codes of ethics of community interpreters tend to emphasize impartiality, the documents defining the emerging profile of intercultural mediators position advocacy more prominently. Beyond the differences in ethical positioning, the article also considers other reasons for the formation of this new profile and outlines several challenges related to the partial overlap between the two profiles, which include distorted definitions of the interpreter's competences and performance, conceptual confusion in the research literature, and mismatched expectations of language services consumers.

Keywords: ethics, codes of conduct, standards of practice, intercultural mediators, community interpreters

\section{Introduction}

This article differentiates between two profiles that seem to compete in parts of the European market: the community interpreter and the intercultural mediator. The European language services market includes a number of professional profiles regularly subsumed under the label "intercultural mediator." The term may define mediators involved in cultural conflict prevention and resolution or refer to community interpreters. It is also used by EU institutions for language experts with multiple areas of language expertise, and it may denote non-professional interpreters (mainly in healthcare settings), who define their role as distinct from 
that of healthcare or community interpreters. This article examines the difference between community interpreters and those intercultural mediators who work as non-professional interpreters, primarily in healthcare settings, and whose role is defined somewhat differently than those of community and healthcare interpreters.

By analyzing a corpus of 13 deontological documents that define the role and the ethical positioning of community interpreters and intercultural mediators, the article investigates how the ethical imperatives of these two profiles differ and whether the reasons for the formation of the new profile of the intercultural mediator are truly only deontological. This type of study requires working definitions of these concepts so as to ensure appropriate comparisons can be made, which we provide in the next section. From there, we examine the profiles of both professionals and non-professionals working as intercultural mediators in Europe in conjunction with the extant literature that differentiates these two profiles. The corpus composition, analysis, and discussion follow, along with some recommendations related to the ethical positioning of these different profiles.

\section{Overlapping definitions and competing profiles}

Several key terms in this article - such as community interpreting, ad hoc interpreting, codes of ethics and standards of practice, ethics and deontology - have a range of definitions within Translation Studies (TS) and related white papers, or the literature proposes alternative terms for the same concepts. Here, community interpreting is defined in line with the international standard "Interpreting - Guidelines for community interpreting" (ISO 13611: 2014), which refers to the activity of "oral and signed communication that enables access to services for people who have limited proficiency in the language of such services." According to this standard, community interpreters assist people who do not speak the societal language or who do not speak it well enough to enable them to access services provided by public institutions (such as schools, universities, and community centers), healthcare institutions, or human and social services (e.g., refugee boards and selfhelp centers). Furthermore, the standard stipulates that they also assist individuals who are not proficient in the societal language to participate in different events organized by faith-based organizations and help in emergency situations. Community interpreters may also be called public service interpreters, interpreters in institutional discourse, dialogue interpreters, or liaison interpreters.

Interpreting can be performed by professional or non-professional interpreters. The term "professional interpreter" in this article refers to those individuals who have received training in the provision of oral or signed translational 
activity and are committed to abide by the profession's codes of ethics and conduct. We will use the term non-professional or ad hoc interpreter to refer to those individuals who have no interpreter training but may practice community interpreting as a full-time or part-time professional activity. Such interpreters may or may not have been exposed to or abide by professional codes of ethics. Typically, they would be asked to interpret because of the lack of qualified and trained professional interpreters for specific language combinations (Mikkelson 1996). Ad hoc interpreters are sometimes also called "untrained" or "bilingual" interpreters.

Here, we also distinguish between the terms ethics and deontology. When we use the term "ethics" on its own, it refers to relations between Self and Other (Pym 2001: 133) and depends on the individual practitioner's integrity. In contrast, the term "deontology" refers to normative ethics that are typically expressed in codes of ethics (Lambert 2018:270), which define the rules and regulations that practitioners are obligated to follow (see Baixauli-Olmos 2017).

Some documents analyzed in this article fall into the category of codes of ethics. Professional codes of ethics are documents that outline best practices in a profession and give guidance on conduct and deontological orientation to practitioners and users of the services (e.g., Mikkelson 2016:77). ${ }^{1}$ These deontological documents are usually drafted by a professional association to regulate behavior and provide an ethical framework that outlines the professional standards that hold interpreters accountable (Swabey and Mickelson 2008; Phelan 2020b: 87). Codes of ethics are closely connected to standards (or codes) of practice or guidelines. Though the boundaries between the two types of texts are not always clear, there is a tendency to call a particular document a code of ethics if it defines what is "right" and what is "wrong" in a profession, whereas standards of practice provide guidance and examples on how to implement ethical principles to promote high quality service (cf. Phelan 2020a: 87). Generally, codes of ethics are relatively short and typically contain basic values of the profession. Standards of practice, however, tend to be created by professional organizations at a later stage, and they are typically longer, more specific, and contain specific scenarios which exemplify adherence to the canons in the code of ethics. The term "deontological documents" will be used as a hypernym for both: codes of ethics and standards of practice (Baixauli-Olmos 2017). And finally, scholarly literature on ethics in interpreting has repeatedly argued that there is a common mismatch between the reality of the interpreters' working environment and the principles expressed in codes of ethics and standards of practice (e.g., Mikkelson 2000; Inghilleri 2005; Angelelli 2006; Marzocchi 2005; Ozolins 2014a; Drugan 2017; Pokorn 2017).

1. Professional codes of ethics are also sometimes referred to as codes of conduct or codes of professional responsibility. 
While extensive treatment of this distinction is beyond the scope of this article, we recognize the existence of this important imbalance. Therefore, we will consider the codes and standards as documents that provide deontological orientation and that, at least nominally, determine the ethical framework of a particular profile.

\section{Intercultural mediators}

The term "intercultural mediator" is used for various profiles of different legal status working in a range of settings in Europe, and it would be impossible to categorize or describe all of them within the scope of the present article. Instead, we describe the most common, current understandings of the term in Europe. First, in parts of Spain the term can be synonymous with the term community interpreter; however, other parts of the country consider these two profiles as being distinct professions. Some training programs incorporate public service interpreting and translation with intercultural communication, which, depending on the program, may or may not cover both types of professional activities. ${ }^{2}$

Second, in other environments intercultural mediators are mainly involved in cultural conflict prevention and resolution. According to the 2013 survey conducted by the Directorate General for Immigration and Integration Policy, which gathered data from 11 member states, only two states - namely, France and the United Kingdom - professionally recognize the qualification of intercultural mediators. ${ }^{3}$ In the UK, intercultural mediation is understood as a type of civil mediation - i.e., a process aimed at amicable settlement of disputes between private subjects (Integrazione Migranti 2015). In France, cultural mediation is considered to be a part of social mediation, that is, an activity aimed at resolving conflicts between individuals or groups or between institutions and individuals (see Wennerström et al. 2001). According to the 2013 survey, intercultural mediators are also used in Belgium to facilitate contacts between the Roma community and local authorities, and in the Czech Republic, where they mainly assist migrants when applying for or renewing their residence permits. In Germany and Austria, individuals whose principal task is to help their clients orient themselves in society are called integration facilitators [Integrationslotsen] (Lietz 2017: 48-50).

2. It should be added that in Catalonia, the term intercultural mediator can also be used for individuals who work in cultural conflict prevention (see Llevot 2004 and Gil Bardají 2020).

3. The Member States included in this study were Belgium, Finland, France, Germany, Greece, Ireland, Portugal, United Kingdom, Czech Republic, Slovakia, and Slovenia. 
Third, in some institutional EU settings, "intercultural mediation" is used as a collective term for a variety of different services provided by the EU translation departments. For example, within the framework of the European Parliament Directorate General for Translation (DG TRAD) the term "intercultural mediator" is used for those professionals who adapt or transform "an existing text according to the needs of a specific target audience, culture or medium while retaining its main concepts," provide support for the production of multilingual video content, moderate the European Parliament's social media content, organize training sessions and workshops (e.g., on how to write clearly in English, how the DG TRAD works, how to use machine translation and the IATE terminology base, and how to create texts of good technical and formatting quality), and support EP communication campaigns and events (DG TRAD Catalogue of Services 2019).

Fourth, the term "intercultural mediators" may refer to individuals who, among other tasks, provide interpreting services and intercultural mediation (see also Verrept 2008; Phelan 2020b). For example, in Germany a new professional profile of "language and integration mediators" (Sprach- und Integrationsmittler/ in) is described as an amalgamation of the profiles "community interpreter," "integration assistant," and "language and cultural mediator," and their principle task is to "overcome barriers to communication and assist education, social and health professionals with integration work" (Becker, Grebe, and Leopold 2010: 9). ${ }^{4}$ Similarly, the published reports produced within the Erasmus+ project Train Intercultural Mediators for a Multicultural Europe (TIME) define intercultural mediators as those individuals who facilitate "the integration process through the removal of both linguistic and cultural barriers" (Olympic Training and Consulting 2015a:3; see also Chiarenza, Dall'Asta, and Ciannameo 2017). In fact, according to the report of World Health Organization Regional Office for Europe (Verrept 2019: 6), the main task of "many intercultural mediators is to facilitate linguistic exchange, which nearly always includes (linguistic) interpreting." Proponents of this group of intercultural mediators thus argue that the profile of this emerging profession, in fact, subsumes the roles of healthcare and community interpreters:

A variety of terms are currently in use to describe the tasks performed by intercultural mediators. Some terms widely used in Europe are linguistic mediation, linkworker, ethnic minority health counselor, bridgeperson, intercultural interpreter, liaison interpreting, community interpreting, dialogue interpreting and public service interpreting.

(Olympic Training and Consulting 2015b: 6)

4. All translations are our own unless otherwise indicated. 
Although interpreting is one of the main tasks of this group of intercultural mediators (Verrept 2008:188), advocates of this emerging profession also admit that intercultural mediators are presently non-professional interpreters: for example, Becker, Grebe, and Leopold (2010:10) observe that language and integration mediators need not be as intensively trained as interpreters and may not have perfect mastery of the German language. Similarly, in the Italian context, the official proposal for a national vocational qualification prepared by Melandri, Carbonari, and Ricci (2014) states that intercultural mediators are expected to be able to perform only "non-professional interpretation." Therefore, as Roman Lietz (2017:48) argues, based on the analysis of the varying cultural and linguistic transfer practices in the German market, the individuals who perform intercultural mediation in Germany today are typically not trained in interpreting. Similarly, Health Evidence Network Synthesis Report 64 describes intercultural mediators as practitioners who "have limited, or no, training in interpreting" (Verrept 2019: 13).

Despite this avowed lack of interpreter training of intercultural mediators, proponents of intercultural mediation in this configuration do not identify the fundamental difference between intercultural mediation and community interpreting in terms of interpreter training, and instead ascribe this difference to their abilities and tasks. Generally, intercultural mediators are argued to possess a more extensive list of skills and competences than community interpreters. Becker, Grebe, and Leopold (2010:10-11), for instance, claim that language and integration mediators "can contribute skills - especially necessary, basic technical knowledge and terminology in social services, education and health - that are not necessarily included in pure interpreting training," and that they do so "at reasonable costs." This statement suggests a devaluing of interpreting education by ignoring the communicative function of interpreting and by failing to attribute the acquisition of extralinguistic knowledge and specialized terminology to this academic preparation.

The difference between interpreters and intercultural mediators is also similarly outlined in the recent WHO Health Evidence Network Synthesis Report 64, in which interpreters are described as those professionals who focus "on resolving language barriers through mediating spoken messages between people speaking different languages without adding, omitting or distorting meaning" (Verrept 2019:48), while intercultural mediators are described as those individuals who, in addition to resolving language barriers, focus "on ensuring comprehension/ understanding of messages exchanged between care provider and patient and facilitating the care provider-patient relationship" (Verrept 2019:48). Verrept here seems to suggest that while interpreters overcome language barriers without necessarily achieving mutual comprehension, the intercultural mediators ultimately 
ensure mutual understanding. ${ }^{5}$ These unsubstantiated claims reduce interpreters to mere conduits of a linguistic code without taking into account meaning or culture and liken them to machines mechanically replacing source-language linguistic items with some near-equivalents from the target language. The EU project TIME also fails to take into account current conceptions of interpreting and is more explicit in this mischaracterization:

The aim of interpretation is to convey the meanings of what is said during an interpersonal encounter as accurately as possible. Intercultural mediation is a much wider and a more enriched means of communicating messages from sender to receiver and vice versa. Thus, intercultural mediation is a bridging of cultures, meanings, silent languages, terms, collocations. /.../ Interpretation differs from intercultural mediation mainly in so far [sic] as it focuses mostly on the language structure and not on the inner meanings of a message.

(Theodosiou and Aspioti 2015: 16-17, emphasis original)

This terminological fuzziness and the fact that interpreting for public services is claimed to be performed by two distinct profiles of practitioners can lead to considerable confusion, in particular since the term "intercultural mediator" is, in some cases, used for two or three of the previously-described profiles, even within the same country. The situation in Italy exemplifies the complexity of the issue. Since Italy was not an immigration-receiving country until the late 1980 s, legislation concerning integration was adopted later than in some of its European counterparts. The earliest legislative decree concerning immigration dates to 1998 (DL 40/1998, see Schuster 2005 for a brief overview). In this legal document and those that followed, the term intercultural mediator (mediatore interculturale) is used

5. This WHO report, which claims to provide a review of 82 academic and gray literature publications on intercultural mediators, merits careful analysis, particularly regarding the ways in which publications from the field of community interpreting (e.g., Hsieh 2016; Angelelli 2004, 2006) are characterized. For instance, publications that focus on the situation in the U.S. and Canada (e.g., California Standards for Healthcare Interpreters) are often used in support of the reduction of interpreting to a mechanical replacement of source-language words by targetlanguage words instead of providing the nuanced discussion that appears in the literature. To give just one example, Verrept (2019:9, emphasis added) writes: "In this context, the intercultural mediator has been described as an intermediary who helps to construct shared meanings in the search for conflict resolution [51]." Reference 51 refers to an article by Boss-Prieto et al. (2010: 14, emphasis added) that reads: "The interpreter is not a translator of words, but an intermediary that helps the construction of meanings between two linguistic worlds in the search for conflict resolution." Verrept (2019) thus uses an article in which interpreters are defined as the constructors of meaning to support his claim that, contrary to interpreters, the intercultural mediators are those who help construct shared meanings. This is not the only instance in which previous research has been mischaracterized in the report. 
without defining either the competences or the tasks of the profile. ${ }^{6}$ The subsequent use of this term, without any reference to the existence of the interpreting profession, has given rise to various interpretations in the following decades.

In Italy, at least three understandings of intercultural mediators prevail, which are similar to those defined above: ${ }^{7}$

1. Intercultural mediators are equated with community interpreters, whose tasks include linguistic and cultural mediation;

2. Intercultural mediators are considered specialists in conflict prevention and resolution;

3. Intercultural mediators are understood as community integration facilitators and non-professional interpreters whose profile is distinct from that of interpreters.

Each of these definitions has been supported by different groups. Interpreting scholars often defend the argument that the term intercultural mediator is basically another term for a community interpreter (Falbo 2013; Schuster 2005; Cirillo 2010; Mometti 2014). Falbo (2013:34-37) argues that since language and culture are inseparable, linguistic and cultural mediation are in fact intrinsic to the job of the interpreter, whose task is to facilitate communication between speakers of different languages and cultures. The competences and tasks of the profile have been implemented in the UNI 11591:2015 standard, in which different specialized profiles of translators and interpreters are defined, including community interpreters in healthcare and social settings and court interpreters. A certifying procedure has been established, with the Associazione italiana traduttori e interpreti [Italian Association of Translators and Interpreters] as the certifying body. Although the aim of the UNI 11591: 2015 standard is to regulate the field, it probably will not be successful in this regard since regional education centers and accreditation bodies are not bound by any national regulations. ${ }^{8}$

6. Different legal documents, regional bodies, and official and unofficial entities have employed terms such as mother-tongue mediators, intercultural mediators, qualified cultural mediators, linguistic mediators, and linguistic and cultural mediators, with various more or less overlapping meanings (Youmbi 2011). Here, we will use the term "intercultural mediator," which is also found in the proposal for the Italian national vocational qualification.

7. As in the above case, this is necessarily an oversimplification, as mixtures of these three views are also in use, along with other, less clearly defined conceptualizations.

8. While there are no national regulations for intercultural mediators in Italy, the profile has been defined and accredited in several Italian regions. These regional profiles display a certain variance and are valid only within the confines of the region where the particular profile was accredited. 
The second conceptualization is used, for instance, by the Associazione Italiana Risoluzione Alternativa Conflitti [Italian Association for Alternative Conflict Resolution, AIRAC], which lists cultural mediators among other dispute resolution agents such as family mediators and arbiters. Here, cultural mediation is understood as a series of interventions aimed at facilitating social integration of foreign families and individuals by providing information about Italian culture and society.

The third profile of intercultural mediators, understood as community interpreters with additional competences, emerged when Italy witnessed increased immigration from areas with languages traditionally not included in translation or interpreting studies programs and for which professional interpreters were not available. According to the promoters of this new profession, who drew up the proposal for a national vocational qualification (Melandri, Carbonari, and Ricci 2014: 14), the intercultural mediator is a profile that provides a wider range of services than the (community) interpreter, as he/she is:

a social operator who is able to carry out interventions of linguistic-cultural mediation, non-professional interpreting and translation and social mediation; promote intercultural mediation as a system device in integration policies; optimize the network and improve the organization and delivery of services; strengthen the professional role of the mediator and transfer the know how to junior mediators and service operators.

According to the national vocational qualification proposal, professional intercultural mediators only need to supplement their work experience with some brief and basic interpreting and translation training, after which they would then be expected to perform non-professional interpretation and translation. This requirement differs from that of professional community interpreters who have been trained at several Italian university programs at the MA level.

In sum, the term "intercultural mediator" in the European context can describe individuals who perform different or similar tasks compared to community interpreters. In this article we focus on intercultural mediators who define their role as distinct from that of community interpreters and who work as nonprofessional, untrained interpreters (mainly in healthcare or other community settings).

\section{Differentiating community interpreters and intercultural mediators}

Even though the profile of the community interpreter and that of the intercultural mediator are both in use with these largely overlapping meanings, few comparisons 
of the two professions have been made. There are, however, some notable exceptions, particularly the analyses carried out by Pöchhacker (2008) and Martín and Phelan (2010).

The concepts of mediation and interpreting were first juxtaposed in interpreting studies in Pöchhacker's (2008) article "Interpreting as mediation," in which he argues that terminological indeterminacy hampers the professionalization of community interpreting in many countries. According to Pöchhacker, the term "mediation" can be understood as a successful transfer between languages and cultures (linguistic mediation), as an inevitably personal transfer of message from the producer of the discourse to the receiver (cognitive mediation), but it can also be understood as successful resolution of intercultural conflicts and differences (contractual mediation). Taking all these meanings of the term into account, he concludes that "[e]very interpreter is a mediator (between languages and cultures), but not every mediator is an interpreter" (Pöchhacker 2008:14). Second, when discussing the distinction between community interpreters and intercultural mediators in German-speaking environments and in Italy, Pöchhacker argues that interpreting and translation tasks in community-based settings have been taken over by mediators employed by various migrant-oriented NGOs because established translator and interpreter training institutions have not met the increased need for intercultural mediators in recent years (Pöchhacker 2008:20-21). With the emergence of intercultural mediators who, among other things, performed interpreting tasks, the distinction between community interpreters and intercultural mediators became imperative, and it was only possible if promoters of intercultural mediation limited the notion of interpreting to linguistic transfer only (Pöchhacker 2008: 21). Pöchhacker concludes that to professionalize community interpreting, a clear distinction should be made between community interpreting and mediation, in particular when the mediation involves social relations and aims to resolve intercultural differences (Pöchhacker 2008: 9).

Similarly, Martín and Phelan (2010) observe that the terms "interpreter" and "intercultural mediator" are used interchangeably in France, Italy, parts of Belgium, and Germany, and that the role boundaries between the two are unclear (see also Phelan 2020b). Focusing on the situation in Ireland, they argue that despite this confusion, the roles of intercultural mediators and interpreters are different and should remain separate. They focus on healthcare to illustrate the difference between the two profiles. According to Martín and Phelan, in healthcare settings intercultural mediators should be called upon initially to help healthcare users access and navigate the system. They should also provide relevant cultural information to both healthcare providers and healthcare users, prevent conflict, and mediate in situations where conflict has already erupted. 
Intercultural mediators should therefore aim to empower healthcare users by informing them of their rights and helping them make choices. Once the task of the cultural mediator is complete, according to Martín and Phelan, community interpreters should be engaged to interpret the communication between the healthcare provider and the healthcare users during the medical examination (e.g., admission, history-taking, therapeutic encounters, discharge, etc.). Martín and Phelan argue that community interpreters should allow the primary speakers in the interpreter-mediated conversation to sort out cultural problems themselves by allowing them to ask more questions and that they should provide a cultural explanation only as a last resort.

The most ardent proponents of intercultural mediators, like Theodosiou and Aspioti (2015), attempt to redefine the profession of community interpreters by reducing the interpreters to mindless machines in order to replace them with intercultural mediators who are supposed to subsume the competences traditionally ascribed to community interpreters. Pöchhacker (2008:26) and Martín and Phelan (2010) reject this simplification of the role and competences of the community interpreter and insist on drawing a difference between these profiles, but they nevertheless conclude that both profiles are necessary and required in the market.

\section{Methodology}

\section{Corpus composition}

To select the documents to analyze the ethical positioning of the intercultural mediator and community interpreter profiles, we first consulted the following surveys of deontological documents for interpreters: Schweda Nicholson (1994); Mikkelson (2000); Bancroft (2005); Hale (2007); Ozolins (2014b); Mikkelson (2016); and Baixauli-Olmos (2017). Some of these surveys focused on deontological documents that were not directly relevant for our study. For example, Mikkelson reviewed selected codes of ethics for court interpreting (2016:75-96), and Bancroft, in her 2005 survey of 145 deontological documents in 11 languages from 25 countries, found no standards of practice that exclusively focus on community interpreting. Despite the varying degrees of applicability to our study, these surveys provided a basis for our selection of the corpus since, as Bancroft argues, medical interpreting standards address many community interpreting issues (Bancroft 2005:39).

We then conducted an internet search and consulted the Translation Studies Bibliography. We have not limited our search to European documents only, since 
community interpreting is an internationally recognized profession (see ISO 13611: 2014) and is not limited to one particular state, region, or continent. In addition, we have assumed that community interpreters may consult the codes and practices that provide ethical guidance and are freely available on the internet, even if they are not members of a particular association (cf. Hernandez-Iverson 2010). Since ISO 13611: 2014 defines healthcare interpreters as a subcategory of community interpreters, we also decided to include in our corpus the codes and standards focusing on healthcare and medical interpreters. We have thus identified six deontological documents that explicitly address community or public service interpreters. We did not limit our search to documents in English only; however, in order to facilitate the analysis, we used the English version of the identified documents (e.g., in the case of the Finnish Code of Ethics for Community Interpreters). In our search, we excluded deontological documents for signlanguage interpreters to enable comparison with the deontological documents of intercultural mediators, which focus only on those mediators working with spoken languages. We also excluded documents that were the work of a particular researcher or practitioner (e.g., Verrept and Coune 2016) or business entity, such as a training agency (e.g., García-Beyaert et al. 2015), since we wanted to get insight into the documents that have been accepted by large groups of practitioners or stakeholders.

The following criteria were adopted to select the documents included in the corpus:

a. The document focuses on spoken and not signed languages.

b. The document explicitly addresses community interpreters.

c. The document addresses medical or healthcare interpreters.

d. The English language version of the document was used if multiple languages were available.

e. The document originated from a public body or a professional association.

Documents that define the ethical positioning of intercultural mediators are much scarcer. For example, Martín and Phelan (2010) found "no recognized, unified code of practice" for intercultural mediators. We identified only two documents that were comparable to the selected deontological documents of community interpreters using the above-mentioned criteria and that discussed deontology of intercultural mediators: the first one was developed within the European project TIME (Train Intercultural Mediators for a Multicultural Europe), and the second was published by the WHO's European regional office. Despite the fact that they are not called standards or codes, these documents include definitions and specifications of ethical positionings of intercultural mediators. The TIME document details the roles and deontology of intercultural mediators, and the WHO docu- 
ment, Annex 2 in particular, compares the roles and ethical positioning of intercultural mediators and community interpreters. Although both documents were created in Europe, they aim beyond the geographical limits of Europe. For example, the TIME project was endorsed by the Japan Chapter Chair of the IMIA, and the WHO document is based on a review of 82 academic and gray literature publications, with $14 \%$ originating in the United States and Canada (Verrept 2019: vii). The final corpus comprises 13 documents (Table 1), which are divided into three categories.

Table 1. Documents included in the corpus

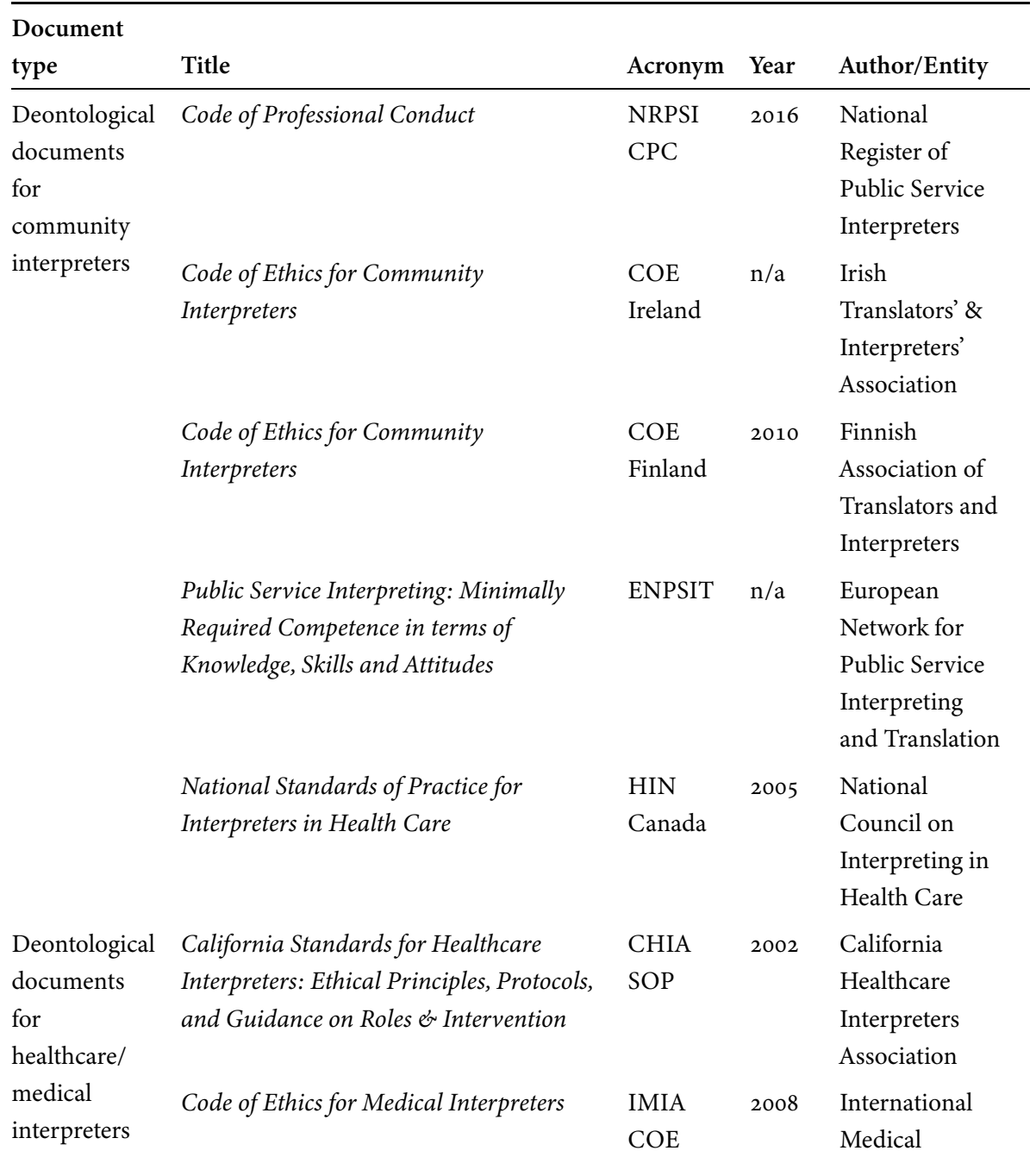


Table 1. (continued)

\begin{tabular}{|c|c|c|c|c|}
\hline $\begin{array}{l}\text { Document } \\
\text { type }\end{array}$ & Title & Acronym & Year & Author/Entity \\
\hline & & & & Interpreters \\
\hline & & & & Association \\
\hline & IMIA Guide on Medical Interpreter & IMIA MI & 2010 & International \\
\hline & Ethical Conduct & & & Medical \\
\hline & & & & Interpreters \\
\hline & & & & Association \\
\hline & Medical Interpreting Standards of & IMIA & 2007 & International \\
\hline & Practice & SOP & & Medical \\
\hline & & & & Interpreters \\
\hline & & & & Association \\
\hline & National Standards of Practice for & NCIHC & 2005 & National \\
\hline & Interpreters in Health Care & NSP & & Council on \\
\hline & & & & Interpreting in \\
\hline & & & & Health Care \\
\hline & A National Code of Ethics for Interpreters & NCIHC & 2004 & The National \\
\hline & in Health Care & NCOE & & Council on \\
\hline & & & & Interpreting in \\
\hline & & & & Health Care \\
\hline \multirow{13}{*}{$\begin{array}{l}\text { Documents } \\
\text { on the ethical } \\
\text { positioning of } \\
\text { intercultural } \\
\text { mediators }\end{array}$} & Intercultural Mediator Profile and & TIME & 2015 & TIME. Train \\
\hline & Related Learning Outcomes & & & Intercultural \\
\hline & & & & Mediators for a \\
\hline & & & & Multicultural \\
\hline & & & & Europe \\
\hline & Health Evidence Network Synthesis & WHO & 2019 & World Health \\
\hline & Report 64. What are the roles of & & & Organization \\
\hline & intercultural mediators in health care and & & & Regional Office \\
\hline & what is the evidence on their contributions & & & for Europe \\
\hline & and effectiveness in improving & & & \\
\hline & accessibility and quality of care for & & & \\
\hline & refugees and migrants in the $\mathrm{WHO}$ & & & \\
\hline & European Region? & & & \\
\hline
\end{tabular}

\section{Analysis}

The texts were analyzed by two researchers who inductively derived a series of categories for analysis following the grounded theory framework (Corbin and Strauss 2008). Coding was completed using NVivo. The two researchers could 
consult on discrepancies to rearrange categories as needed and to resolve ambiguities until redundancy was reached. Seven main categories and 15 subcategories were coded. Table 2 presents the coding scheme that was developed on the basis of their analysis. Here, we focus on the profile, role, competences, and ethical positioning of these two profiles. ${ }^{9}$

Table 2. Coding typology for the analyzed data

\begin{tabular}{|c|c|c|c|c|c|}
\hline \multirow{2}{*}{$\begin{array}{l}\text { Profile } \\
\text { Competences }\end{array}$} & \multicolumn{5}{|c|}{ community interpreter intercultural mediator } \\
\hline & $\begin{array}{l}\text { conflict } \\
\text { resolution and } \\
\text { mediation } \\
\text { competence }\end{array}$ & $\begin{array}{l}\text { cultural } \\
\text { competence }\end{array}$ & $\begin{array}{l}\text { thematic } \\
\text { competence (e.g., } \\
\text { knowledge of the } \\
\text { topic) }\end{array}$ & $\begin{array}{l}\text { linguistic } \\
\text { competence }\end{array}$ & $\begin{array}{l}\text { transfer } \\
\text { competence }\end{array}$ \\
\hline $\begin{array}{l}\text { Mention of } \\
\text { ethics }\end{array}$ & explicit mention & \multicolumn{4}{|c|}{ implicit mention } \\
\hline $\begin{array}{l}\text { Ethical } \\
\text { principles }\end{array}$ & $\begin{array}{l}\text { advocacy, } \\
\text { empowerment }\end{array}$ & \multicolumn{2}{|c|}{ confidentiality } & \multicolumn{2}{|c|}{$\begin{array}{l}\text { impartiality, neutrality, } \\
\text { equal distance }\end{array}$} \\
\hline Training & type of training & \multicolumn{2}{|c|}{ duration of training } & \multicolumn{2}{|c|}{ level of training } \\
\hline \multicolumn{6}{|c|}{ Definition of main role } \\
\hline \multicolumn{6}{|c|}{ Legal text references } \\
\hline
\end{tabular}

\section{Results}

Table 3 summarizes the number of times each category was coded in each text. The main codes with aggregated numbers for all the relative sub-codes are marked in bold. The subcategory "Other" comprises other references to ethical principles, such as integrity or professionalism, which lie outside the scope of this study.

Not all of the texts chosen for the analysis mention both profiles (see Table 3). In fact, apart from the TIME and WHO documents, which explicitly attempt to distinguish between community interpreters and intercultural mediators, both profiles are referred to in only three of the documents aimed at healthcare interpreters (CHIA SOP, IMIA COE, and IMIA MI), while intercultural mediators are not mentioned at all in the first set of deontological documents, which focus explicitly on community interpreters.

9. Alternative terms, such as public service interpreter, healthcare interpreter, medical interpreter, and cultural mediator, mentioned in the previous sections, were respectively aggregated under the terms community interpreter and intercultural mediator. 


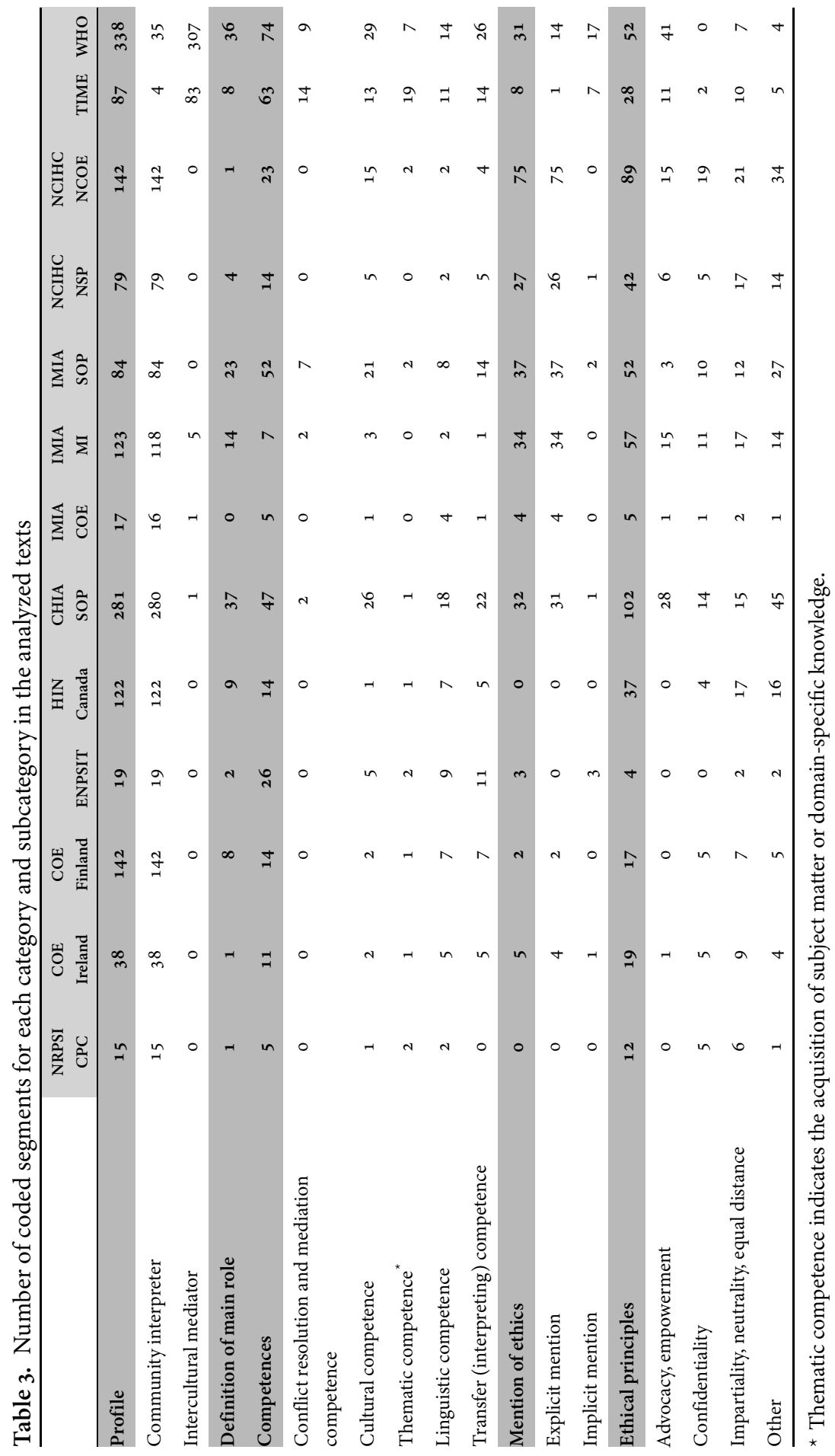


The definitions of the main role(s) of community interpreters or intercultural mediators are present in all of the analyzed texts, except in the IMIA COE text, which is linked to two documents from the same organization (IMIA MI and IMIA SOP), where the definition is provided. The most detailed description of the role of a community interpreter is found in the CHIA SOP text $(n=37),{ }^{10}$ which distinguishes between the roles of message converter, message clarifier, cultural clarifier, and patient advocate. And finally, the role of intercultural mediators is extensively described in both the WHO $(n=36)$ and TIME texts $(n=8)$.

The analysis of the deontological documents shows that there is indeed overlap between the two profiles, since we could identify all the defined categories in the two documents that focus on intercultural mediators and one document that focuses on community interpreters (CHIA SOP). Other deontological documents contain, to a varying degree, only some of the categories defined. The inclusion of an individual category, however, only indicates that a particular topic is discussed in a particular document, but not the attitude taken toward this topic in the document.

\section{Expected competences}

The differences between the two profiles become clearer when we investigate the competences that community interpreters and intercultural mediators are expected to have. Five distinct competences (or sets of competences) were analyzed. Three appear in all of the analyzed documents: linguistic competence, cultural competence, and transfer competence. This last competence, namely transfer, typically refers to interpreting, but in some instances, can also include written translation. Thematic competence - i.e., factual knowledge about the institutions and fields in which community interpreters/intercultural mediators work - is explicitly mentioned in all but three texts (IMIA COE, IMIA MI, and NCIHC NSP), although it is often also implicitly included in reference to linguistic or cultural competences. In addition, the WHO and TIME documents mention this competence much more frequently than the others. The most striking difference among the three sets of analyzed texts, potentially linked to advocacy (albeit not explicitly described as such), is related to the conflict resolution and mediation competence, mentioned in only five texts (TIME, WHO, IMIA MI, IMIA SOP, and CHIA SOP). The textual analysis reveals that this competence is seen in the IMIA MI text as being outside the scope of the work of a medical interpreter, while the CHIA SOP and IMIA SOP texts view this competence as

10. Angelelli (2006) has discussed the reception of the standards set out in CHIA SOP by professional healthcare interpreters and the difficulties in applying the standards in practice. 
being linked primarily to the optional role of a patient advocate, which should be undertaken only by the most experienced interpreters. However, in the TIME and WHO texts, the conflict resolution and mediation competence assumes the central role.

The definition of ethical principles listed in the deontological document

Out of the three ethical principles analyzed, impartiality (also termed "neutrality" or "equal distance") appears in all documents (see Table 3). All the texts analyzed explicitly refer to this ethical stance, and the TIME text even states that this is the "default position" (TIME: 10) of the intercultural mediator. ${ }^{11}$ However, there are some interesting differences. The first set of deontological documents, which focuses on community interpreters, tends to stress that impartiality is the only acceptable positioning for a community interpreter, while the CHIA SOP text (also, less explicitly, the NCIHC NCOE text) from the second set, which focuses on healthcare interpreters, promotes an "incremental intervention model" (CHIA SOP: 49), according to which specific situations may call for different approaches and standpoints. ${ }^{12}$ Similarly, the WHO and TIME texts advocate impartiality until the situation requires a different level of involvement.

Confidentiality is explicitly dealt with in all analyzed texts except the ENPSIT and WHO texts. However, the ENPSIT text explicitly refers to "adherence to the highest standards of professional conduct and ethics" (ENPSIT: 4), so we may assume that it also includes this principle, since confidentiality is present in other deontological documents that provide guidance to community interpreters.

Advocacy was coded when an explicitly-stated intent was present in the document - e.g., the NCIHC NSP text reads: "The interpreter may advocate on behalf of a party or group to correct mistreatment or abuse" (NCIHC NSP: 10). Advocacy was also coded when the reference was implicit but nevertheless quite recognizable, as in the case of the TIME text when it defines the competences of

11. In interpreting studies, the terms position and positioning are used in different ways; they may refer to the continuously changing nature of interaction among the participants in interpreter-mediated communication (e.g., Mason 2009) or the physical position of the interpreter in face-to-face encounters (e.g., Pokorn 2017). Here, we use the terms to refer to the preferable ethical stance taken by a practitioner.

12. The issue of impartiality has been critically discussed by several interpreting studies scholars (e.g., Rudvin 2007; Prunč 2012). For example, while Ozolins (2016) identified the principle of impartiality as the core principle for professional practice, Downie (2017) defended the need to critique the current professional discourse through empirical research and argued that the term impartiality should be abandoned as an analytical term in favor of agency. This issue, despite its relevance, is beyond the scope of this article. 
cultural mediators: "Knowledge of exclusion and discrimination mechanisms" (TIME: 25). The reference to the principle of advocacy was thus found in nine texts, five of which also mention intercultural mediators (WHO, TIME, CHIA SOP, IMIA COE, and IMIA MI), while four texts (COE Ireland, IMIA SOP, NCIHC NCOE, and NCIHC NSP) focus exclusively on community interpreters. The attitude toward advocacy varies from text to text. In the COE Ireland text, for example, advocacy is explicitly advised against: "[the community interpreter] is not employed by the beneficiary and should not act as their advocate" (COE Ireland: 1). In the IMIA COE, IMIA MI, and IMIA SOP texts, advocacy is provisionally accepted: community interpreters are advised to "engage in patient advocacy and in the intercultural mediation role of explaining cultural differences/ practices to health care providers and patients only when appropriate and necessary for communication purposes" (IMIA COE: 1). And finally, in CHIA SOP, NCIHC NCOE, and NCIHC NSP, the patient advocate is considered to be one of the possible roles the healthcare interpreter can assume. The issue of advocacy is not problematized in NCIHC NCOE and NCIHC NSP, where the interpreter is expected to "advocate on behalf of a party or group to correct mistreatment or abuse" or "to speak out to protect an individual from serious harm" (NCIHC NSP: 10), while more caution is advised in CHIA SOP. In fact, it is argued in the California Standards that "interpreters may play a role in eventually affecting change by documenting problems and raising the issues appropriately" (CHIA SOP: 62).

However, the California Standards also stress that the role of an advocate requires great experience and skill and involves a number of ethical dilemmas (such as the risk of compromising patient autonomy) and potential negative consequences for the patient and interpreter (such as resentment against the interpreter, diminished quality of care or access for the patient, or a less effective working relationship between the interpreter and the service provider), about which the community interpreter should reflect carefully before abandoning an impartial positioning. Much less caution toward advocacy is present in the documents focusing on intercultural mediators. The WHO and TIME texts give a central role to advocacy, which they seem to see as one of the fundamental characteristics of the intercultural mediator's profile. Although the neutral position is stated as the default position in both documents, advocacy is considered necessary and desirable. For example, the WHO text, when comparing the profile of an interpreter to that of an intercultural mediator (WHO: 48-49), argues that while interpreters focus on impartiality and neutrality, intercultural mediators also assume a position that is by default impartial and neutral - but it immediately adds that in addition to impartiality they display "an additional focus on 
inequity/inequality" and that their "explicit mission is patient empowerment and advocacy" (WHO: 49).

\section{Discussion}

The analysis of the literature and the corpus presented above shows that there is a high degree of confusion and overlap between the profile of community interpreter and that of the intercultural mediator, if intercultural mediators are defined as individuals who, among other tasks, provide interpreting services and intercultural mediation. Although the roles, competences, and deontology of community interpreters and intercultural mediators are largely similar, this overlap is not absolute, and there are some significant differences between the expected roles of both profiles that need to be made more visible.

The above comparison of the competences and ethical imperatives has shown that in general two elements seem to differentiate the two profiles: first, the presence or absence of conflict management, and second, the issue of impartiality versus advocacy. Unlike interpreters, intercultural mediators are expected to get involved in conflict prevention and resolution. They also see their role as proactive in assisting and instructing service providers to act in a culturally competent way (e.g., WHO: 49). On the other hand, the deontological documents of community interpreters in general do not envisage conflict management as one of the tasks of community interpreters. Similarly, the deontological documents of community interpreters overwhelmingly tend to uphold the principle of neutrality and impartiality, while the documents defining the ethical positioning of intercultural mediators are invariably open to advocacy. There is one deontological document focusing on community interpreting that differs from all the others: the California Standards for Healthcare Interpreters: Ethical Principles, Protocols, and Guidance on Roles \& Intervention (CHIA SOP). These standards allow conflict management, cultural instruction, and advocacy in healthcare settings; however, they warn against potential negative consequences of advocacy and reserve this ethical stance only for exceptional cases and only for the most experienced and skilled interpreters. So, while the documents defining the role and ethical positioning of the intercultural mediators see advocacy as an acceptable response in situations when "the principle of equal opportunities is violated or the dignity/ rights of the weaker party are attacked" (TIME: 10) and even define empowerment and advocacy as an "explicit mission" of intercultural mediators (WHO: 49), the deontological documents of community interpreters tend to warn against it (COE Ireland). 
The profiles of community interpreters and intercultural mediators, in particular those who work in healthcare, have considerable overlap, but they also differ significantly, in particular regarding ethical positioning when interpreting in intercultural encounters. This partial overlap and the conflicting ethical imperatives might be, in the best-case scenario, confusing for the service providers and users of the interpreting or mediation services, and in the worst case, it may generate distorted expectations of the interpreter's or mediator's competences and performance.

\section{Conclusion}

The corpus analysis has shown that the main difference between the profession of community interpreters and the emerging profession of intercultural mediators with respect to ethical positioning and role lies in their ethical imperatives, with the codes and standards for intercultural mediators stressing advocacy as a key task of this emerging profession. The fact that deontological documents for intercultural mediators, however, also include the principle of impartiality and often mirror aspects of the deontological documents for community and healthcare interpreters raises the question of whether the promotion and emergence of this new profile are really the result of an insistence on just a different ethical stance, or whether there are other reasons as well. So, is it really all about ethics?

From our perspective, it appears that the reasons why this new profile of intercultural mediators in Europe has emerged are diverse and should not be reduced solely to issues surrounding ethics. Below, we provide some other possible causes for this situation.

First, the established European institutions that train interpreters and translators did not respond to the pressing need for interpreters in languages that were not traditionally taught - in general, they lacked qualified trainers for the languages of newly arrived migrants and were unable to attract a sufficient number of students since potential candidates from newly arrived migrant groups tended not to have the prerequisite level of education (see Balogh et al. 2016). Therefore, NGOs, organizations, and institutions working with migrants were unable to find enough professional interpreters to meet demand and consequently resorted to anyone who could potentially help bridge the language barriers (see Ozolins 2010 on the role of NGOs in interpreter provision). Intercultural mediation thus arose as a reaction to the increased presence of refugees and migrants who spoke languages that were not taught at the majority of the European interpreter and translator training programs. 
Second, sociologists, cultural anthropologists, and other non-language specialists who work with migrants through NGOs and other organizations soon recognized the need to train ad hoc interpreters from these newly arrived migrant groups and to professionalize what they termed "intercultural mediation." In doing so, this group of specialists realized that there already existed a recognized professional figure with a very similar profile in the market, namely the community interpreter. In their fight for dominance in the training of language specialists for the needs of the migrant population, they therefore decided to emphasize the difference between the two profiles by downplaying the communicative function of interpreting and reducing the community interpreter to a mere conduit who "focuses mostly on the language structure and not on the inner meanings of a message" (Theodosiou and Aspioti 2015:17).

Third, the need for intercultural mediators, i.e., individuals who would not only interpret the communication between the service provider and the user but also assume a more active role in medical treatment, is sometimes uncritically called for by service providers themselves. The results of Verrept's (2008:195) qualitative evaluation studies show that "[some] health professionals asked intercultural mediators to perform tasks that should normally be performed by themselves." The anecdotal evidence of the tendency of healthcare workers to transfer some of their obligations to mediators was also provided at the stakeholders' forum (Trieste, 31 November 2019) of a project titled Training Newly Arrived Migrants for Community Interpreting and Intercultural Mediation (TRAMIG). For instance, a gynecologist participating at the forum described that she sometimes asked the mediators/interpreters, who were not healthcare specialists, to explain complex medical issues (such as the dangers of diabetes or female genital mutilation) to her patients.

In sum, despite the overlapping competences outlined above and in view of the potentially different ethical standpoints of the two profiles (see also Viezzi 2019), we believe that there is space in the market for both professions. Certain tasks are dyadic in nature and ultimately require a bilingual speaker; however, they may not require the services of an interpreter. Intercultural mediators may be well-suited for certain tasks identified by the WHO and TIME project, such as providing information on the available health and social services and on healthcare entitlements, providing psychosocial support (including acting as liaison inside and outside medical settings), health education and promotion and cotherapy (in mental health settings) (WHO: vii-viii), or providing information to migrants regarding administrative procedures, access to services and supportive resources, and assistance in navigating the services (accompaniment, paperwork etc.) and contributing to informal events and projects in order to raise awareness and enhance intercultural communication and integration (TIME: 4-5). On the 
other hand, in every triadic communication that necessarily involves interpreting between two speakers (or groups of speakers) of different languages, we believe that we should insist on the use of trained interpreting professionals.

To conclude, this brief analysis of the documents that define the ethical positioning and profiles of community interpreters and intercultural mediators shows that stakeholders and the general public must be made aware of the nature of interpreting work and of the need of professional interpreting service provision, particularly in high-risk, multilingual communicative events, such as in asylum procedures, hospitals, courts, or when dealing with the police or social services, i.e., in situations where unskilled help might result in negative life-changing or life-threatening events.

\section{Funding}

This research was co-funded by the Erasmus+ programme of the European Union (Project TRAMIG, no. 604596-EPP-1-2018-1-SI-EPPKA3-IPI-SOC-IN) and by the Slovenian Research Agency (research core funding No. P6-0239 and P6-0218). The European Commission support for the production of this publication does not constitute endorsement of the contents which reflects the views only of the authors, and the Commission cannot be held responsible for any use which may be made of the information contained therein.

\section{References}

\section{Primary sources}

California Healthcare Interpreters Association. 2002. California Standards for Healthcare Interpreters: Ethical Principles, Protocols, and Guidance on Roles \& Intervention. www .chiaonline.org/resources/Pictures/CHIA_standards_manual_\%2oMarch\%202017.pdf. Last accessed 27 February 2020.

Finnish Association of Translators and Interpreters. 2010. Code of Ethics for Community Interpreters. http://wasli.org/wp-content/uploads/2013/10/8o_coe-svt.pdf. Last accessed 27 February 2020.

Hernandez-Iverson, Eva. 2010. IMIA Guide on Medical Interpreter Ethical Conduct, International Medical Interpreters Association. www.imiaweb.org/uploads/pages/376_2.pdf. Last accessed 27 February 2020.

HIN. 2007. National Standard Guide for Community Interpreting Services. www.saludycultura .uji.es/archivos/HIN_National_Standard_Guide_for_CI_(Canada).pdf. Last accessed 27 February 2020.

International Medical Interpreters Association \& Education Development Center. 2007. Medical Interpreting Standards of Practice. www.imiaweb.org/uploads/pages/102.pdf. Last accessed 27 February 2020. 
International Medical Interpreters Association. 2008. Code of Ethics for Medical Interpreters. www.imiaweb.org/uploads/pages/376.pdf. Last accessed 27 February 2020.

Irish Translators' \& Interpreters' Association. Code of Ethics for Community Interpreters. www .translatorsassociation.ie/wp-content/uploads/2017/o3/Code-of-Ethics-for-CommunityInterpreters.pdf. Last accessed 3 November 2019.

National Council on Interpreting in Health Care. 2004. A National Code of Ethics for Interpreters in Health Care. www.ncihc.org/assets/documents/publications /NCIHC\%20National\%20Code\%20of\%20Ethics.pdf. Last accessed 27 February 2020.

National Council on Interpreting in Health Care. 2005. National Standards of Practice for Interpreters in Health Care. www.ncihc.org/assets/documents/publications /NCIHC\%20National\%20Standards\%20of\%20Practice.pdf. Last accessed 27 February 2020.

National Register of Public Service Interpreters. 2016. Code of Professional Conduct. www .nrpsi.org.uk/for-clients-of-interpreters/code-of-professional-conduct.html. Last accessed 27 February 2020.

Remael, Aline, Jan Cambridge, Ulrike Fuhrer, Heidi Salaets, and Carmen Valero-Garcés. Public Service Interpreting: Minimally Required Competence in Terms of Knowledge, Skills and Attitudes. www.enpsit.org/uploads/1/1/3/8/113822115/t_a-document_1-competences _skills.pdf. Last accessed 27 February 2020.

TIME. Train Intercultural Mediators for a Multicultural Europe. 2015. Intercultural Mediator Profile and Related Learning Outcomes. www.mediation-time.eu/images/TIME_O3 _intercultural_mediator_profile.pdf. Last accessed 27 February 2020.

Verrept, Hans. 2019. Health Evidence Network Synthesis Report 64. What are the roles of intercultural mediators in health care and what is the evidence on their contributions and effectiveness in improving accessibility and quality of care for refugees and migrants in the WHO European Region? World Health Organization Regional Office for Europe. www .euro.who.int/_data/assets/pdf_file/o014/406004/WHO-HEN-Report-64-SummaryWeb.pdf. Last accessed 27 February 2020.

\section{Secondary Sources}

AIRAC - Associazione Italiana Risoluzione Alternativa Conflitti. Codice deontologico. https://airac.it/lassociazione/codice-deontologico/. Last accessed 27 February 2020.

Angelelli, Claudia V. 2004. Medical Interpreting and Cross-cultural Communication. New York: Cambridge University Press. https://doi.org/10.1017/CBO9780511486616

Angelelli, Claudia V. 2006. "Validating professional standards and codes: Challenges and opportunities." Interpreting 8 (2): 175-193. https://doi.org/10.1075/intp.8.2.04ang

Baixauli-Olmos, L. 2017. "Ethics codes as tools for change in public service interpreting: Symbolic, social and cultural dimensions." The Journal of Specialised Translation 28: 250-272.

Balogh, Katalin, Heidi Salaets, and Dominique Van Schoor (eds). 2016. TraiLLD: Training in Languages of Lesser Diffusion. Leuven: Lannoo Campus.

Bancroft, Marjory. 2005. The Interpreter's World Tour: An Environmental Scan of Standards of Practice for Interpreters. USA: National Council on Interpreters in Health Care.

Becker, Carsten, Tim Grebe, and Enrico Leopold. 2010. Sprach- und Integrationsmittler/-in als neuer Beruf: Eine qualitative Studie zu Beschäftigungspotenzialen, Angebotsstrukturen und Kundenpräferenzen. Wuppertal: Diakonie Wuppertal. 
Boss-Prieto, Olga, et al. 2010. "Differences in therapeutic alliance when working with an interpreter: A preliminary study." Schweizer Archiv fur Neurologie und Psychiatrie 161 (1): 14-16. https://doi.org/10.4414/sanp.2010.02127

Chiarenza, Antonio, Ilaria Dall'Asta, and Anna Ciannameo. 2017. "Intercultural mediation as part of a system strategy in the AUSL of Reggio Emilia." Presentation given at the Exchange Seminar on Intercultural Mediation, 17-18 November 2017, Reggio Emilia, Italy.

Cirillo, Letizia. 2010. "La riparazione come meccanismo di coordinamento nell'interazione medico-paziente mediata da interprete." In Mediazione tra prassi e cultura: oltre i risultati di una ricerca, ed. by Danilo De Luise and Mara Morelli, 13-30. Monza: Polimetrica International Publisher.

Corbin, Juliet and Anselm Strauss. 2008. Basics of Qualitative Research: Techniques and Procedures for Developing Grounded Theory. Thousand Oaks, CA: Sage Publications. https://doi.org/10.4135/9781452230153

DL 40/1998. Disciplina dell'immigrazione e norme sulla condizione dello straniero www .camera.it/parlam/leggi/98040l.htm. Last accessed 27 February 2020.

Downie, Jonathan. 2017. "Finding and critiquing the invisible interpreter - A response to Uldis Ozolins." Interpreting 19 (2): 260-270. https://doi.org/10.1075/intp.19.2.05dow

Drugan, Joanna. 2017. "Ethics and social responsibility in practice: Interpreters and translators engaging with and beyond the professions." The Translator 23 (2): 126-142. https://doi.org/10.1080/13556509.2017.1281204

Falbo, Caterina. 2013. La comunicazione interlinguistica in ambito giuridico. Temi problemi e prospettive di ricerca. Trieste: Edizioni Università di Trieste.

García Beyaert, Sofia, et al. 2015. "Ethics and standards for the community interpreter. An international training tool." In The Community Interpreter: An International Textbook, ed. by Marjory A. Bancroft et al., 68-88. Columbia, SC: Culture and Language Press.

Gil-Bardají. 2020. "Ethics, accuracy, and interpreting in social settings." Translation and Interpreting Studies 15 (1). https://doi.org/10.1075/tis.20008.gil

Hale, Sandra Beatriz. 2007. Community Interpreting. London: Palgrave Macmillan. https://doi.org/10.1057/9780230593442

Hsieh, Elaine. 2016. Bilingual Health Communication: Working with Interpreters in Crosscultural Care. New York: Routledge. https://doi.org/10.4324/9781315658308

Inghilleri, Moira. 2005. "Mediating zones of uncertainty: Interpreter agency, the interpreting habitus and political asylum adjudication." The Translator 11 (1): 69-85. https://doi.org/10.1080/13556509.2005.10799190

Integrazione Migranti. 2015. Intercultural Mediation. www.integrazionemigranti.gov.it/en /latest-news/highlights/Pages/INTERCULTURAL\%2oMEDIATION /European\%2oUnion\%2oand\%20comparative\%2oframework.aspx. Accessed 27 October 2019.

ISO 13611. 2014. Interpreting - Guidelines for Community Interpreting. Geneva: ISO.

Lambert, Joseph. 2018. "How ethical are codes of ethics? Using illusions of neutrality to sell translations." The Journal of Specialised Translation 30: 269-290.

Lietz, Roman. 2017. Professionalisierung und Qualitätssicherung in der Integrationsarbeit: Kriterien zur Umsetzung von Intergrationslotsenprojekten. Opladen: Budrich UniPress.

Llevot Calvet, Núria. 2004. "Conflictos culturales y mediación: el ejemplo de Cataluña." Revista de Educación 334: 415-432. 
Martín, Mayte C. and Mary Phelan. 2010. "Interpreters and Cultural Mediators - Different but complementary roles." Translocations: Migration and Social Change: An InterDisciplinary Open Access E-Journal 6 (1).

Marzocchi, Carlo. 2005. "On norms and ethics in the discourse on interpreting." The Interpreters' Newsletter 13: 87-107.

Mason, Ian. 2009. "Role, positioning and discourse in face-to-face interpreting." In Interpreting and Translating in Public Service Settings, ed. by Raquel de Pedro Ricoy, Isabelle Perez, and Christine Wilson, 52-73. Manchester: St. Jerome.

Melandri, Elisabetta, Lucia Carbonari, and Annunziata Ricci. 2014. La qualifica del mediatore interculturale. Contributi per il suo inserimento nel futuro sistema nazionale di certificazione delle competenze. Dossier di sintesi. Gruppo di Lavoro Istituzionale sulla mediazione interculturale.

Mikkelson, Holly. 1996. "Community interpreting: An emerging profession." Interpreting 1 (1): 125-129. https://doi.org/10.1075/intp.1.1.08mik

Mikkelson, Holly. 2000. "Interpreter ethics: A review of the traditional and electronic literature." Interpreting 5 (1): 49-56. https://doi.org/10.1075/intp.5.1.05mik

Mikkelson, Holly. 2016. Introduction to Court Interpreting. Second edition. London: Routledge. https://doi.org/10.4324/9781315689586

Mometti, Francesca. 2014. "Il diritto all'assistenza linguistica dell'imputato straniero nel procedimento penale. Indagine conoscitiva presso il tribunale di Trieste." In Traduzione e interpretazione per la società e le istituzioni, ed. by Caterina Falbo and Maurizio Viezzi, 131-141. Trieste: Edizioni Università di Trieste.

Olympic Training and Consulting (ed.). 2015a. Intercultural Mediator Profile and Related Learning Outcomes. www.mediation-time.eu/images/TIME_O3_intercultural_mediator _profile.pdf. Last accessed 3 November 2019.

Olympic Training and Consulting (ed.) 2015b. Self-study Course for Trainers of Intercultural Mediators: Module 7, Resources on Intercultural Mediation. www.mediation-time.eu /images/TIME_O5_Trainer_Course_Module_7.pdf. Last accessed 3 November 2019.

Ozolins, Uldis. 2010. "Factors that determine the provision of Public Service Interpreting: Comparative perspectives on government motivation and language service implementation." The Journal of Specialised Translation 14: 194-215.

Ozolins, Uldis. 2014a. "Descriptions of interpreting and their ethical consequences." FITISPos International Journal 1 (1): 23-41.

Ozolins, Uldis. 2014b. "Rewriting the AUSIT Code of Ethics - Principles, practice, dispute." Babel 60 (3): 347-70. https://doi.org/10.1075/babel.60.3.050zu

Ozolins, Uldis. 2016. "The myth of the myth of invisibility?" Interpreting 18 (2): 273-284. https://doi.org/10.1075/intp.18.2.06ozo

Phelan, Mary. 2020a. “Association codes of ethics." In Ethics in Public Service Interpreting, ed. by Mary Phelan, Mette Rudvin, Hanne Skaaden, and Patrick Stefan Kermit, 87-98. Abingdon: Routledge.

Phelan, Mary. 202ob. "Intercultural mediators." In Ethics in Public Service Interpreting, ed. by Mary Phelan, Mette Rudvin, Hanne Skaaden, Patrick Stefan Kermit, 120-121. Abingdon: Routledge.

Pöchhacker, Franz. 2008. “Interpreting as mediation." In Crossing Borders in Community Interpreting: Definitions and Dilemmas, ed. by Carmen Valero-Garcés and Anne Martin, 9-26. Amsterdam: John Benjamins. https://doi.org/10.1075/btl.76.02poc 
Pokorn, Nike K. 2017. “There is always some spatial limitation: Spatial positioning and seating arrangement in healthcare interpreting." Translation and Interpreting Studies 12 (3): 383-404. https://doi.org/10.1075/tis.12.3.02pok

Prunč, Erich. 2012. "Rights, realities and responsibilities in community interpreting." The Interpreters' Newsletter 17: 1-12.

Pym, Anthony. 2001. "Introduction." The Translator 7 (2): 129-138. https://doi.org/10.1080/13556509.2001.10799096

Rudvin, Mette. 2007. "Professionalism and ethics in community interpreting: The impact of individualist versus collective group identity." Interpreting 9 (1): 47-69. https://doi.org/10.1075/intp.9.1.04rud

Schuster, Chiara. 2005. "Role and status of public service interpreters in Italy today: A perspective from regional and national policies." In Traducción como mediación entre lenguas y culturas, ed. by Carmen Valero Garcés, 17-26. Madrid: Universidad de Alcalá.

Schweda Nicholson, Nancy. 1994. "Professional ethics for court and community interpreters." In Professional Issues for Translators and Interpreters, ed. by Deanna L. Hammond, 79-98. Amsterdam: John Benjamins. https://doi.org/10.1075/ata.vii.10sch

Swabey, Laurie and Paula Gajewski Mickelson. 2008. "Role definition: A perspective on forty years of professionalism in Sign Language interpreting." In Crossing Borders in Community Interpreting: Definitions and Dilemmas, ed. by Carmen Valero-Garcés and Anne Martin, 51-80. Amsterdam: John Benjamins. https://doi.org/10.1075/btl.76.04swa

Wennerström, Erik, et al. 2001. Social Mediation and New Methods of Conflict Resolution in Daily Life: Proceedings of the Seminar Organised by the Interministerial Delegation for Urban Affairs under the French Presidency of the European Union - Oisin Programme, Paris-Créteil. Saint-Denis-la-Plaine: Éditions de la DIV.

Theodosiou, Aspasia and Maria Aspioti (eds). 2015. Research Report on Intercultural Mediation for Immigrants in Europe. http://mediation-time.eu/images/TIME_O1_Research_Report _v.2016.pdf. Accessed 3 November 2019.

UNI 11591:2015. Attività professionali non regolamentate. Figure professionali operanti nel campo della traduzione e dell'interpretazione. Requisiti di conoscenza, abilità e competenza.

Verrept, Hans. 2008. "Intercultural mediation: An answer to health care disparities?" In Crossing Borders in Community Interpreting: Definitions and Dilemmas, ed. by Carmen Valero-Garcés and Anne Martin, 87-202. Amsterdam: John Benjamins. https://doi.org/10.1075/btl.76.10ver

Verrept, Hans and Isabelle Coune. 2016. Guide for Intercultural Mediation in Health Care. Brussels: FPS Health, Safety of the Food Chain and Environment. www.health.belgium .be/sites/default/files/uploads/fields/fpshealth_theme_file/2017_11_14_guide_english_o .pdf. Accessed 18 February 2020.

Viezzi, Maurizio. 2019. "La sfida del multilingualismo. Riflessioni su lingua e lingue, traduzione e interpretazione." In Annali dell'Istituto Armando Curcio, ed. by Sabrina Aulitto and Graziano Benelli, 231-276. Rome: Istituto Armando Curcio University Press.

Youmbi, Raymond Siebetcheu. 2011. "Identità e ruolo del mediatore linguistico-culturale in Italia." The Journal of Cultural Mediation 1: 7-16. 


\section{Address for correspondence}

Nike K. Pokorn

Department of Translation Studies, Faculty of Arts

University of Ljubljana

Aškerčeva 2

1000 Ljubljana

Slovenia

nike.pokorn@ff.uni-lj.si

\section{Biographical notes}

Nike K. Pokorn is Professor in Translation Studies at the University of Ljubljana and the current director of the International Doctorate in Translation Studies network. She is co-editor of Why Translation Studies Matters and author of Challenging the Traditional Axioms: Translation into a non-mother tongue and Post-Socialist Translation Practices.

(iD) https://orcid.org/o0oo-0002-2152-612X

Tamara Mikolič Južnič is Assistant Professor in Translation Studies at the University of Ljubljana. Her research interests include translation flows in peripheral languages, translator and interpreter training, contrastive linguistics, and corpus linguistics. She has published articles in the fields of translation studies and linguistics and monographs in Slovene and English. She is also an active translator specializing in technical and scientific texts.

(iD) https://orcid.org/0000-0003-2731-8660 